\title{
Siyah kıllı dil: vaka serisi
}

\section{Black hairy tongue: a case series}

\author{
Yasemin Korkut ${ }^{1}$, Nazlı Dizen Namdar ${ }^{2}$ \\ ${ }^{1}$ Aile Hekimliği Ana Bilim Dalı, Tıp Fakültesi, Dumlupınar Üniversitesi, Kütahya, Türkiye \\ ${ }^{2}$ Deri ve Zührevi Hastalıklar Ana Bilim Dalı, Tıp Fakültesi, Dumlupınar Üniversitesi, Kütahya, Türkiye
}

\section{ÖZET}

Giriş: Siyah kıllı dil; filiform papillaların dil dorsumunda deskuame olamaması ve hipertrofisi sonucu kadifemsi plak oluşturması durumudur.

Vaka Sunumu: Polikliniğimize farklı şikâyetlerle başvuran siyah kıllı dil tespit edilen dört hasta vaka olarak sunulmuştur.

Tartışma: Siyah kıllı dilin etyopatogenezi tam olarak bilinmemekle birlikte pek çok predispozan faktör ileri sürülmüştür. Tanısı klinik bulgular ve öyküye dayalı olan siyah kıllı dil tedavisinde tetikleyici faktörlerin önlenmesi, gıda ve su alımının düzenlenmesi, dilin mekanik temizliği önemlidir. Antiseptik solüsyonlar, topikal tretinoin diğer tedaviler arasındadır.

Sonuç: Aile hekimleri birinci basamakta sigara içen hastalarında nadiren de olsa siyah kıllı dil gelişebileceğini göz önünde bulundurmalidir.

Anahtar kelimeler: Siyah kıllı dil; kıllı dil/tanı; filiform papilla; hiperkeratoz

\begin{abstract}
Introduction: Black hairy tongue occurs as a result of inability desquamation and hyperthrophy of filiforme papilla on the dorsum of the tongue which also cause as the creation of velvety plaques.

Case Presentation: Four patients with black hairy tongue who were referred to our clinic with different complaints were presented as cases.

Discussion: Although the etiopathogenesis of the black hairy louse is not completely known, many predisposing factors have been proposed. Prevention of triggering factors, the regulation of food and water, mechanical cleaning of the language is important in the treatment of black hairy tongue. Medical treatment includes antiseptic solutions, topical tretinoin.

Conclusion: Family physicians should consider that in first-stage smokers patients may rarely develop black hairy language.

Keywords: Black hairy tongue; Tongue, Hairy/diagnosis; filiform papilla; hyperkeratosis
\end{abstract}

Başvuru / Submission: Ocak / Jan 03, 2017

Kabul / Acceptance: Nisan / Apr 18, 2017

Yazışma / Correspondence: Yrd. Doç. Dr. Yasemin Korkut, Tavşanlı yolu 10. Km Dumlupınar Üniversitesi Tıp Fakültesi Aile Hekimliği A.D. Kütahya, Türkiye

E-mail: ykorkut95@yahoo.com

Atıf / Cite: Korkut Y, Namdar ND. Siyah k1llı dil: Vaka serisi. Fam Pract Palliat Care. 2017;2(1):23-25 


\section{GIRIŞ}

Siyah kıllı dil, dilin dorsal yüzeyinde bulunan filiform papillaların hiperplazi ve hiperkeratozu ile karakterize benign, kazanılmış bir hastalıktır. Dördüncü dekat ve sonrasında daha s1k görülür ${ }^{1,2}$. Etyopatogenez tam olarak bilinmemekle birlikte, aşırı sigara-alkol tüketimi, oral hijyen bozukluğu, bazı ilaçların kullanımı, erkek cinsiyet etyolojide suçlanmıştır. Genellikle asemptomatik olmakla beraber estetik kaygılara neden olabilir. Bazı hastalarda bulantı, öğürme hissi, ağız kokusu, tat duyusunda azalma gözlenebilir ${ }^{3,4,5}$.

Olgu sunumlarımızda, siyah kıllı dil tanısı koyduğumuz dört erkek hasta güncel literatür bilgileri eşliğinde sunulmuş olup bu vasıtayla, hastalığın hatırlatılması, koruyucu tedavide oral hijyene dikkat etmenin önemi ve hastaların bilinçlendirilmesi amaçlanmıştır ${ }^{2}$.

\section{OLGU SUNUMU}

\section{Olgu 1}

22 yaşında erkek hasta, dilinde ortaya çıkan kahverengi lezyon sebebi ile aile hekimliği polikliniğine başvurdu. Hikâyesinde yakınmalarının bir aydır olduğu ve son 4 gündür giderek arttığı, alt solunum yolu enfenksiyonu tanısıyla bir haftadır antibiyotik tedavisi altında olduğu öğrenildi. Oral hijyeni kötü olan hastanın dil dorsumunda yaygın sarıkahverengi hipertrofiye olmuş filiform papillalar gözlendi (Resim 1).

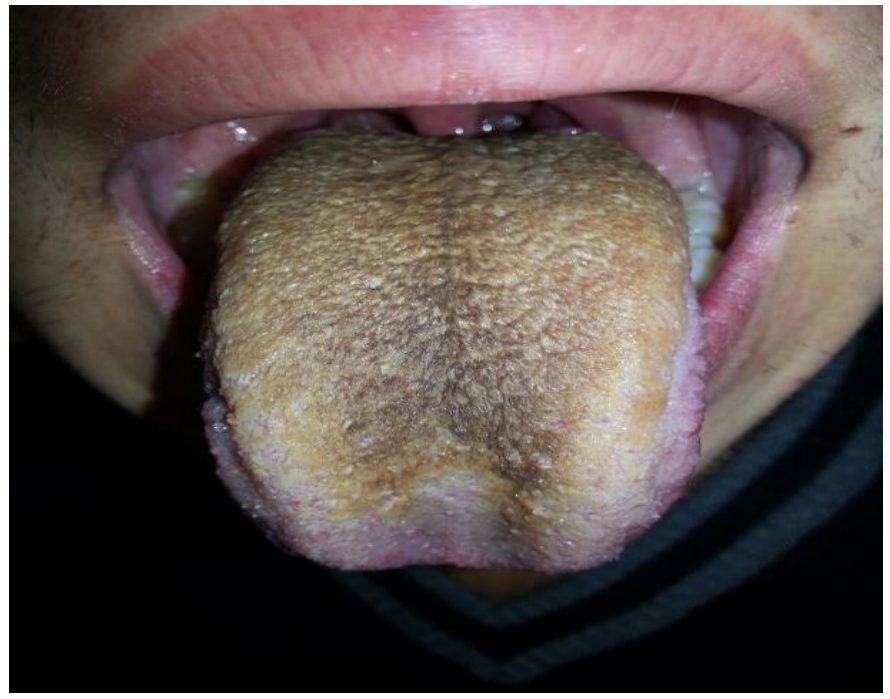

Resim 1. Foremen ceacum'dan başlayan kıllı dil olgusu

\section{Olgu 2}

17 yaşında erkek hasta, dilinde renk değişikliği, ateş ile polikliniğine başvurdu. 2-3 gündür ateş, boğaz ağrisı olduğunu söyleyen hastanın muayenesinde, üst solunum yolu enfeksiyonu tanısı konuldu. 2 yıldır 15 adet/gün sigara kullanım hikâyesi olan hastanın dil üzerinde uzamış filiform papilların bulunduğu kahverengi hiperkeratozik plak lezyon saptandı (Resim 2).

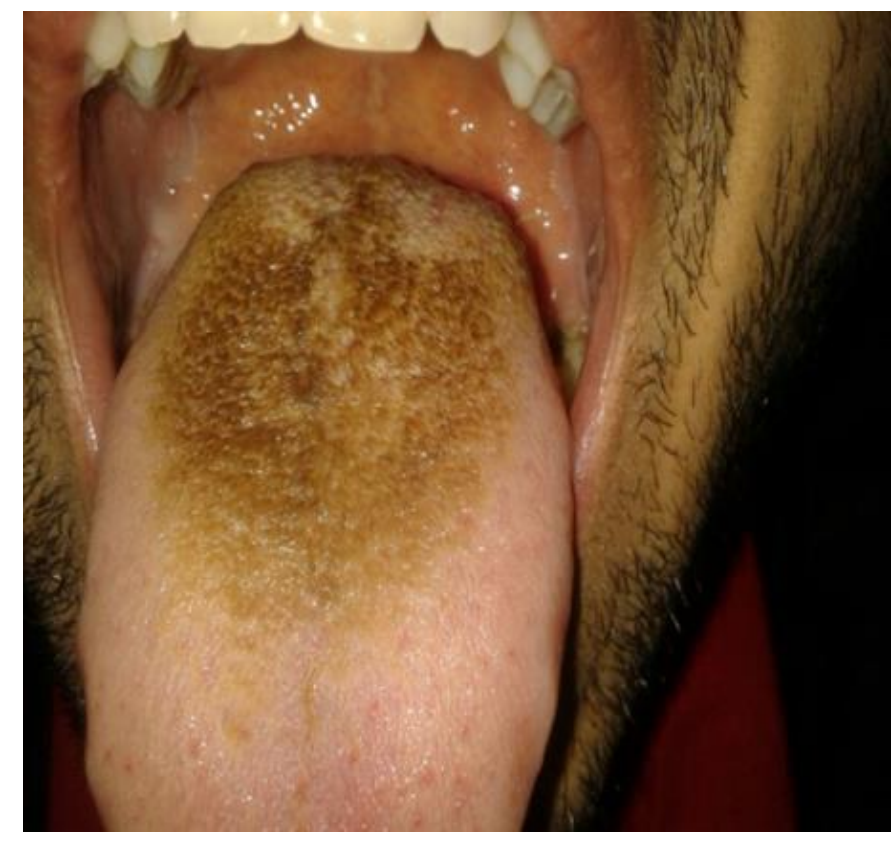

Resim 2. Kahverengi hiperkeratozik plak lezyon

\section{Olgu 3}

33 yaşında erkek hasta tat almada azalma, öksürük, ateş yüksekliği şikâyeti ile polikliniğimize başvurdu. Fizik muayenesinde ateşi $39^{\circ} \mathrm{C}$, tonsiller hiperemik ve hipertrofik, dil üzerinde yaygın sarı-kahverengi hipertrofik plak lezyon üzerinde saça benzer filiform papillalar mevcuttu (Resim 3).

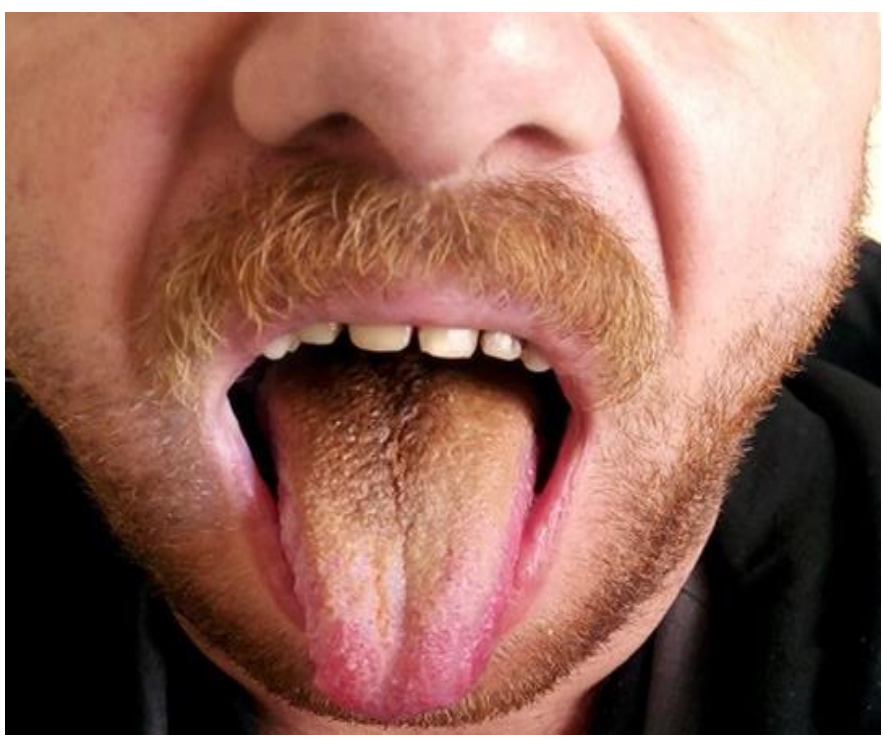

Resim 3. Yaygın sarı-kahverengi hipertrofik plak lezyon

\section{Olgu 4}

58 yaşında bulantı şikâyeti nedeniyle gelen erkek hastanın 30 yıldır 1 paket/gün sigara içme öyküsü mevcuttu. Dil üzerinde yaygın sar1-kahverengi plak lezyon ve dil papillalarında hipertrofi mevcuttu (Resim 4). 


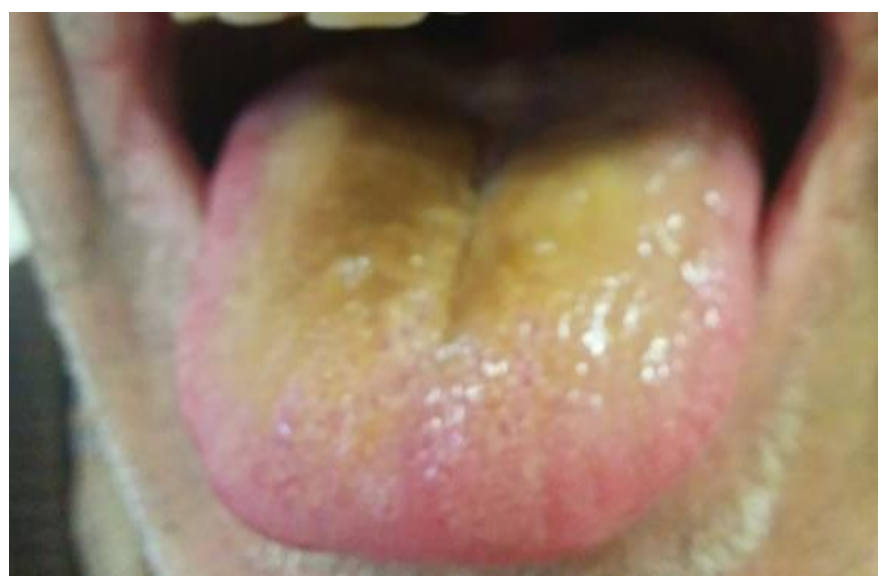

Resim 4. Dil üzerinde yaygın sarı-kahverengi plak lezyon ve dil papillalarında hipertrofi

$\mathrm{Bu}$ bulgular eşliğinde hastalara, siyah kıllı dil tanısı konulduktan sonra sigara içmeme, hijyen gibi hastalıktan koruyucu faktörlerin öneminden özellikle bahsedildi ve tedavi edici olarak da mekanik temizlik, bikarbonatlı oral bakım solüsyonları verildi. Oral hijyen için antiseptik gargara başlandı. Yaklaşık bir ay sonraki kontrollerinde, şikâyetlerinde iyileşme ve lezyonlarda belirgin düzelme gözlendi.

\section{TARTIŞMA}

Siyah Kıllı Dil, dilin dorsal yüzeyinde uzun saça benzer hipertrofik ve uzamış filliform papaillalarla karakterize iyi huylu, edinsel bir durumdur ${ }^{6,7}$. Kill dil siyah, kahverengi, sar1, mavimsi veya gri renkli olabilir, genellikle kendi kendini sinırlayan iyi prognozlu bir hastalıktır ${ }^{8,9}$.

Siyah k1llı dil genellikle asemptomatiktir fakat tat duyusunda azalma, halitozis, ögürme hissi ve estetik görünümle ilgili şikâyetler olabilir.

Etyolojisi tam olarak bilinmese de tetikleyici pek çok ajan üzerinde durulmuştur. Siyah kıllı dilli hastalarda sigara, ileri yaş, erkek cinsiyet, kötü ağız hijyeni, genellikle antibiyotik, antipsikotik, antiasit gibi ilaçların kullanımı, kserostomi, kanser, trigeminal nevralji, bazı maddelerin kötüye kullanımı (kokain vb.), oksitleyici ajan içeren ağız gargaraları (sodyum peroksit, hidrojen peroksit), edinsel immun yetmezlik sendromu tetikleyici durumlardır 1,5,10-14.

Yapılan bazı çalışmalar, sigara kullanımındaki artışla doğru orantılı olarak siyah kıllı dil sıklığında da artış olduğunu göstermiştir ${ }^{15,16}$. Bizim dört hastamızın yaşları, bir vaka hariç görülme dekatına göre daha genç dönemde idi. Hastalarımız, 330 yıl arasında değişen sürelerde ortalama 18 adet /gün sigara kullanım öyküsü ve oral hijyen bozukluğu olan erkek hastalardı. Ek olarak hastalarımızın üçünde enfeksiyon ve iki hastamızda da antibiyotik kullanma öyküsü mevcuttu.

Siyah k1llı dilin tedavisinde topikal veya oral retinoidler, salisilik asit, vitamin B kompleksi, \%40 üre solüsyonları kullanılmaktadır ${ }^{6,17}$. Hastanın dilini firçalayarak yapılan mekanik temizlikte tedavide etkilidir ${ }^{6,18,19}$.

$\mathrm{Bu}$ olgu sunumlarında, üst solunum yolu enfeksiyonu, bulantı ya da estetik kaygılar gibi farklı nedenlerle aile hekimliği polikliniğimize başvuran dört farklı vakayı sunmak istedik.
Hastalar tarafindan her zaman direkt bașvuru sebebi olmasa da orofarenks muayenesi sırasında dikkat edilmesi ve tedavi edilmesi açısından kıllı dil aklımıza gelmesi gereken ve çoğu zaman tanisı atlanabilen bir durumdur.

\section{SONUÇ}

Gerek aile hekimleri gerekse diğer branş hekimlerinin polikliniğe başvuran her hastada sigara içme durumunu, hastaların kullandığı ilaçları sorgulayıp, gerekli davranış ve destek tedavisini vermesi, gelişebilecek diğer hastalıkları ve komplikasyonları önleyecektir.

Çıkar iliş̧kisi: Yoktur.

Finansal destek: Yoktur.

\section{KAYNAKLAR}

1. Gurvits GE, Tan A. Black hairy tongue syndrome. World J Gastroenterol. 2014;21:10845-10850.

2. Kalkan G, Baș Y, Seçkin HY, Karahan S. Altmıș Beș Yașında Diyabetik Kadın Hastada Siyah Kıllı Dil. Selçuk Tıp Derg. 2014;30:184-185.

3. Thompson DF, Kessler TL. Drug- Induced Black Hairy Tongue Pharmacotherapy. 2010;30:585-93.

4. Lawoyia D, Brown RS. Drug-Induced Black Hairy Tongue: Diagnosis and Management Challenges. Dent Today 2008;27:602.

5. Farman AG. Hairy tongue (lingua villosa). J Oral Med. 1977;32:85-91.

6. Heymann WR. Psychotropic agent-induced black hairy tongue. Cutis 2000;66:25-26.

7. Manabe M, Lim HW, Winzer M, Loomis CA. Architectural organization of filiform papillae in normal and black hairy tongue epithelium: disection of differentiation pathways in a complex human epithelium according to their patterns of keratin expression. Arch Dermatol 1999;135:177-181.

8. Kurukahvecioğlu S, Kocatürk S, Yardımeı S. et al. Kıllı dil olgu sunumu. KBB-Forum 2003;2.

9. Essential Otolaryngology Head and Neck Surgery K.J.Lee, 3th Edition Appleton and Lange Stamford, Connecticut, pp:464.

10. Winer L. Black Hairy Tongue. Arch Dermatol 1958;77:97-103.

11. McCarthy F. A clinical and pathologic study of oral disease. JAMA 1941;116:16-21.

12. Avcu N, Kanl1 A. The prevalence of tongue lesions in 5150 Turkish dental outpatients. Oral Dis 2003;9:188-95

13. Jahanbani J, Sandvik L, Lyberg T,3 and Ahlfors E. Evaluation of Oral Mucosal Lesions in 598 Referred Iranian Patients. Open Dent J. 2009; 3: 42-47.

14. Kargın N, Marakoğlu K. Sigara içmeyle ilişkili nadir bir olgu: Siyah dil gelişimi. Türkiye Aile Hekimliği Derg. 2015;19: 97 98.

15. Andersson G, Vala EK, Curvall M. The influence of cigarette consumption and smoking machine yields of tar and nicotine on the nicotine uptake and oral mucosal lesions in smokers. J Oral Pathol Med 1997;26:117-123.

16. Mirbod SM, Ahing SI. Tobacco-associated lesions of the oral cavity: Part I. Nonmalignant lesions. J Can Dent Assoc 2000;66:252-256.

17. Mc Gregor JM, Hay RJ. Oral retinoids to treat black hairs tongue. Clinic Exp Dermatol 1993;18:291.

18. Allen CM, Blozis GG. Oral mucosal lesions. Otolaryngology Head and Neck Surgery. Ed: Cummings CW, Second Edition 1992;76 pp:1379.

19. Chakraborty P, Pulai D. Black Hairy Tongue (Lingua Villosa Nigra). Journal of the association of physicians of İndia 2013;12:61. 